Canadian

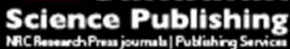

Canadian Journal of Zoology Revue canadienne de zoologie

\title{
Galápagos sperm whales (Physeter macrocephalus): waxing and waning over three decades
}

\begin{tabular}{|r|l|}
\hline Journal: & Canadian Journal of Zoology \\
\hline Manuscript ID & cjz-2016-0266.R1 \\
\hline Manuscript Type: & Article \\
\hline Complete List of Authors: & $\begin{array}{l}\text { Cantor, Mauricio; Dalhousie University, Department of Biology; } \\
\text { Universidade Federal de Santa Catarina, Laboratório de Mamíferos } \\
\text { Aquáticos, Departamento de Ecologia e Zoologia, Centro Ciências } \\
\text { Biológicas } \\
\text { Eguiguren, Ana; Dalhousie University, Department of Biology } \\
\text { Merlen, Godfrey; Isla Santa Cruz } \\
\text { Whitehead, Hal; Department of Biology }\end{array}$ \\
\hline Keyword: & $\begin{array}{l}\text { emigration, El Nino, sperm whale, Physeter macrocephalus, whaling, } \\
\text { CETACEA < Taxon, WHALES < Taxon }\end{array}$ \\
\hline
\end{tabular}


Galápagos sperm whales (Physeter macrocephalus): waxing and waning over three decades

M. Cantor ${ }^{*}$, A. Eguiguren ${ }^{1}$, G. Merlen ${ }^{2}$, H. Whitehead ${ }^{1}$

${ }^{1}$ Department of Biology, Dalhousie University. 1355 Oxford street, Halifax, Nova Scotia B3H 4J1, Canada.

${ }^{2}$ Puerto Ayora, Isla Santa Cruz, Galápagos, Ecuador

* Author for correspondence: Mauricio Cantor. Department of Biology, Dalhousie University, 1355

Oxford Street, B3H 4J1, Halifax, NS, Canada. Phone: +1 902 494-3723 Email: m.cantor@ymail.com

\footnotetext{
1* Current affiliation and address (Mauricio Cantor): Departamento de Ecologia e Zoologia, Universidade Federal de Santa Catarina; Campus Universitário, Trindade, Caixa Postal 5102, CEP 88040-970, Florianópolis, SC, Brazil. E-mail: m.cantor@ymail.com
} 
Galápagos sperm whales (Physeter macrocephalus): waxing and waning over three decades

M. Cantor, A. Eguiguren, G. Merlen, H. Whitehead

\begin{abstract}
While population sizes and structures naturally fluctuate over time, rapid within-generation changes are usually driven by habitat quality shifts and/or abrupt mortality. We evaluate how sperm whales (Physeter macrocephalus, L. 1758 (= Physeter catodon, L. 1758)) responded to the dynamic habit off the Galápagos Islands over 30 years, relating it to variation in prey availability and whaling operations in the tropical Pacific. In the 1980's, males and females were commonly sighted foraging and socializing in the northwest of the archipelago. Sightings decreased during the 1990's; by the 2000's they became very rare: occasional single foraging males were sighted and females abandoned the archipelago. In the 2010's, whales return to the southern waters, in large groups with apparently more breeding males and calves. The waxing and waning of Galápagos sperm whales are likely caused by environmental shifts together with ripple effects of whaling. Their patchy prey are influenced by variation in sea temperature and productivity, which drives movements of whales in and out of the archipelago. Whaling may have aggravated these movements by leaving an attractive surplus of prey in coastal waters depleted of whales. These findings highlight the magnitude of spatiotemporal scales used by sperm whales and the consequent challenges of assessing population dynamics of long-lived, mobile pelagic species.
\end{abstract}

Key-words: El Niño, emigration, sperm whale, Physeter macrocephalus, whaling 
Introduction

Populations change over time. Their size and structure fluctuate as input (natality and immigration) is countered by output of individuals (mortality and emigration) (e.g. Wilson and Bossert 1971). This dynamic is influenced by extrinsic and intrinsic factors, as well as their interactions (Lack 1966; Sutherland 1996). Extrinsic factors principally concern environmental processes. For instance, a local increase in resource availability can promote population growth (e.g. Blake and Loiselle 1991; Adler 1998), while a disease outbreak (e.g. Daszak et al. 2003; Frick et al. 2010) or increase in predator density can result in population decline (e.g. Székely and Bamberger 1992). Intrinsic biological traits of the species determine how the population reacts to such external factors. For example, life history parameters - e.g. reproduction rates, age of sexual maturity, life span, dispersal ability — and population structure-e.g. sex ratio, proportion of individuals in age groups (Lomnicki 1988; Boyce at al. 2006) affect how and at what rate populations fluctuate with changes in habitat quality.

When environment changes, long-lived organisms usually experience relatively less variability in adult survival rates, but relatively more variability in reproduction and survival rates of young individuals, than short-lived organisms (Gaillard and Yoccoz 2003; Rotella et al. 2011). In such cases, adult survival of long-lived organisms is maintained by enduring external stressors (e.g. Bodmer 1990; Villegas-Amtmann et al. in press) or by moving to more suitable habitats when local quality drops beyond a critical level (Fretwell and Lucas 1969; Moore 2005). By allocating resources to survival rather than reproductive rates, populations of long-lived organisms fluctuate less in response to natural environmental changes, but may take substantially longer to recover from drastic changes (Sinclair 1996; de Little et al. 2007).

A notable example of a long-lived species experiencing highly dynamic environments is the sperm whale (Physeter macrocephalus, L. 1758 (= Physeter catodon, L. 1758)). Deep-diving and widely distributed, they are key top predators of mesopelagic food webs (e.g. Paine 2006; Lavery et al. 2010; Roman et al. 2014). With few oceanographic barriers (Jaquet 1996), sperm whales move at various spatial scales (e.g. Whitehead et al. 2008) according to the distribution of their prey-the patchy, short-lived (1-2 years), and understudied deep-sea squids (Whitehead 1996; Nigmatullin et al. 2001; Mizroch and Rice 2013). The abundance and distribution of these squids is subjected to environmental shifts (e.g. Taipe et al. 2001; Markaida 2006), such as El Niño Southern Oscillations (ENSO) that radically affect primary productivity (e.g. Laurie and Brown 1990; Cai et al. 2014). In addition to environmental variability, until 
recently sperm whale populations were exposed to an external pressure causing high mortality. Between 1712 and 1939 large numbers of sperm whales were killed for commerce, but in the 1950's, after the near extinction of most baleen whale stocks, they became the major target of the whaling efforts (Clapham and Baker 2002). Industrial and pirate whalers first concentrated on the large and sexually-mature males, then aimed at females, decimating populations until the whaling moratorium in the 1980's (Whitehead 2002). The sperm whale sexes have widely different adult morphologies (males being about 3 times more massive), distributions (females using tropical and subtropical waters, with males largely at higher latitudes excerpt when breeding) and behaviour (females being much more social); all of which have strongly affected our exploitation practices and attempts to understand the species (e.g. Best et al. 1979; Whitehead 2003).

Long life cycles and wide geographical ranges challenge investigations into sperm whale population dynamics. Yet long-term studies can clarify how their distribution patterns and population structure interact with environmental variation and anthropogenic pressures. Our purpose was to evaluate how sperm whales responded to the dynamic environment of an important portion of their eastern tropical Pacific habitat over the last 30 years following the whaling moratorium. Here, we show how the occurrence of sperm whales fluctuated between 1985 and 2014 off the Galápagos Islands using measures that directly or indirectly indicate habitat use (sighting rates, feeding success, behavioral state, fine scale distribution), population and social structure (sex ratio, cluster and group sizes), and reproductive success (proportion of breeding males and calves). Finally, we investigate variation in these parameters in the light of changes in prey availability and the ripple effects of whaling in the tropical Pacific.

Material and Methods

Study Area

The Galápagos Islands $\left(0^{\circ} 40^{\prime} \mathrm{S}, 90^{\circ} 33^{\prime} \mathrm{W}\right)^{2}$, and more broadly the eastern tropical Pacific, are historically important concentration grounds for sperm whales (Shuster 1983, Whitehead et al. 1997, Smith et al. 2012). The archipelago is located in an upwelling zone that is productive but highly variable (e.g. Villegas-Amtmann et al. in press). Specifically, it is strongly influenced by the multiannual ENSO cycles (Fig. 1). During its warm phase, sea surface temperature rises and primary productivity decreases,

\footnotetext{
${ }^{2}$ Fig. S1
} 
affecting survival across all trophic levels (e.g. Barber and Chavez 1983; Strutton and Chavez 2000; Cai et al. 2014).

\section{Offshore surveys and data sampling}

Between 1985 and 2014, we surveyed the deep waters $(>1,000 \mathrm{~m})$ off the Galápagos archipelago during 2- to 3 -week trips ${ }^{3}$. This time at sea was very largely divided into three survey modes as follows. During Survey Mode A (Searching), we searched haphazardly for sperm whales during day and night, covering quasi-linear transects at an average speed of $5 \mathrm{kn}$, listening for the whales every 30 min through omnidirectional hydrophone arrays (frequency responses: $6 \mathrm{~Hz}-10 \mathrm{kHz}, \pm 3 \mathrm{~dB} ; 1-10 \mathrm{kHz}$, $\pm 3 \mathrm{~dB}$ ). At the same time, we also conducted visual surveys with 1 to 3 observers at the deck ( $2 \mathrm{~m}$ above sea surface) and, weather permitting, also at the crows' nest (9 m). During Survey Mode B (Female tracks), when a group of female sperm whales (sometimes including calves, juveniles or breeding males) was encountered, we tracked visually and acoustically at ranges of about 0.1 to $8 \mathrm{~km}$, for as long as possible. Encounters with groups of females typically lasted 1 to 3 days at time $(\min =2 \mathrm{~h} ; \max =12$ days). During Survey Mode C (Male encounter), when a single male, or small group of males, was encountered, they were typically studied for a few hours before resuming searching (Mode A).

In all three survey modes, we recorded the whales' position from the vessel approximately every 3 hours with SAT-NAV between 1985 and 1991, with GPS every 15 min between 1995 and 1997, and every 1-5 minutes in 2013 and 2014. During daylight, in Modes B and C, we slowly approached individuals from behind to photograph their flukes (tails) when they dived. We used the photographs to identify individual whales through patterns of natural marks on the trailing edge of the flukes, using a semi-automated photo-identification protocol (Whitehead 1990). We rated each photograph from poor to very high quality ( $Q=1$ to 5 ) based on focus, exposure, orientation, percent cover and tilt of the fluke (see Whitehead 2003) and used only $Q \geq 3$ photographs.

We used body size and general behaviour to define age-sex classes (Whitehead 1996, 2003, Christal and Whitehead 1997): distinctively small animals (4-5.5 $\mathrm{m}$ in length) in close proximity with other larger individuals were considered calves; distinctively larger animals ( $>12 \mathrm{~m}$ long) were considered mature males; other animals (mostly 7.5-10.5 $\mathrm{m}$ in length) were considered as bachelor males

\footnotetext{
${ }^{3}$ Table S1
} 
when consistently found alone or in small groups (2-4 individuals), or as adult females and immatures of both sexes when in large groups.

\section{Population descriptors}

We measured ten direct and indirect descriptors of habitat use, social structure, and reproduction of the Galápagos population, defined as follows:

(a) Sighting rates: We calculated annual sighting rates as the number of female tracks (Mode B) per total hours of acoustic and visual search (Mode A) (Whitehead et al. 1997; Cantor et al. 2016a).

(b) Feeding success: We used defecation rates to infer feeding success in the previous $24 \mathrm{~h}$ (Whitehead et al. 1989). Whenever the vessel was suitably placed after the photo-identification attempt, we checked each 'fluke-print' (a visible pattern on the water surface left by an individual whale after diving) to record whether or not it defecated (indicated by the presence of a brown patch in the water). We calculated defecation rate as the number of defecations observed divided by number of fluke-prints examined (during Modes B and C).

(c) Behavioural ratio: For each daylight hour spent following a group of females (Mode B) with sufficient observations, we classified its general behavioural state as foraging or socializing. These two states were defined using the empirical data from 1985-1987 based on cluster size (see below) and rate of long, deep dives ('fluking-up rate') as: $B=(0.278 \cdot c)-(2.030 \cdot f)$, where $c$ is mean cluster size, $f$ is the flukingup rate per whale in $5 \mathrm{~min}$. If $B>0.5$ the whales were considered socializing, and foraging otherwise (in Whitehead and Weilgart 1991). Thus foraging is defined by whales in small (1-3) clusters and performing long and deep dives; and socializing means whales were in larger clusters and mostly at the surface. Since after this analysis the two states became very distinctive, in subsequent years we recorded the general behaviour state at sea in real time during daylight hours (see Whitehead 1999). Here, we calculated the annual behavioural ratio as the proportion of hours spent foraging divided by the number of hours spent foraging or socializing (Mode B).

(d) Cluster size: A cluster of whales is a temporary subset of a group composed of the individuals at the surface swimming in the same direction and speed, side by side in a coordinated manner a few body lengths or less apart usually for a matter of minutes (Whitehead 1999, 2003). To calculate annual average cluster size, we used records of the number of adult individuals in each cluster that we photographed 
during Mode B surveys. To avoid the confounding effect of males (Mode C), we removed from this analysis the clusters with males only.

(e) Group size: A group of whales was defined as a set of individuals that were photo-identified together, moving together in a coordinate manner for hours (Whitehead 1999, 2003). We estimated group sizes using high-quality individual photographic identification data $(Q>3)$ and the Lincoln-Petersen markrecapture estimator, a closed-population abundance estimator that uses two capture occasions. Annual average group size estimates were based on estimates for each day, calculated as: $g=\left[\left(x_{1}+1\right)\left(x_{2}+1\right) /\left(x_{12}+1\right)\right]-1$; where $x_{1}$ are the whales identified in the first half of the photoidentifications on that day, $x_{2}$ in the second half, and $x_{12}$ in both (Whitehead 1999). We calculated annual average group sizes only for females (Mode B), as males are found alone (sometimes in duos and trios) or in transit among female groups for short time periods (Whitehead 2003).

(f) Adult sex ratio: We inferred an annual adult sex ratio by calculating the number of individual adult males per female identified in high-quality photographs $(Q>3)$ while with groups of females (Mode B) in each year.

(g) Calf proportion: We calculated calf sightings as the averaged proportion of calves per year observed in each cluster containing females approached for photo-identification (Mode B). The clusters with only males were excluded from this analysis (Mode C and males sighted during Mode B).

(h) Breeding male proportion: We calculated proportion of breeding males as the number of clusters of females and immatures in which large males were observed in close proximity to them, divided by the total number of female and immature clusters approached for photo-identification (Mode B). Since the abundance of breeding males off the Galápagos seems to vary seasonally (Whitehead 1993), we avoided potential biases by discarding data from months when males were scarcer.

(i) Female clusters: We calculated the total number of clusters of females photo-identified without breeding males (Mode B).

(j) Fine-scale distribution: We created density maps to visualize annual and decadal spatial distribution of sperm whales. With geographic positions collected while searching and tracking groups of females (Modes A, B), we calculate kernel density as a relative measure of the proportion of time spent in different areas around the archipelago. Kernel density creates a probability density function, which accounts for spatial auto-correlation, above each geographical point given a predetermined bandwidth; the resultant cell in a map is the sum of all the density functions that occur within that cell (e.g. 
Matiopoulus 2003). To correct for the variation in sampling intervals across years (from 1 to 180 minutes), we subsampled positions every three hours. We assigned 1 to positions that occurred while tracking groups of females and juveniles (Mode B) and 0 when whales were being searched (Mode A). We calculated the kernel density of presence points for each decade in ArcGIS 10.2.2, using a $2 \mathrm{~km}$ by 2 $\mathrm{km}$ resolution and a bandwidth of $40 \mathrm{~km}$. We chose this bandwidth based on the lower threshold of 24hour displacement of Eastern Pacific female and immature sperm whales (Whitehead 2003, Whitehead and Rendell 2004). We weighted density by effort so that weighted density $\left(p_{w}\right)=p / d$, where $p$ is the raw kernel density of female and juvenile groups and $d$ is the sampling effort. We measured sampling effort as the kernel density of all geographic positions (presences and absences) collected at a $2 \mathrm{~km}$ by 2 $\mathrm{km}$ cell and a $10 \mathrm{~km}$ bandwidth by year (or decade). The $10 \mathrm{~km}$ bandwidth reflected the range at which whales could be detected through hydrophones $(7 \mathrm{~km})$ plus the $3 \mathrm{~km}$ spread of groups of females and immatures (Whitehead 2003). We mapped the distribution of groups with only males (Mode C) by using the first position of the encounter, instead of creating density maps because, in contrast with groups of females and juveniles (Mode B), male groups were often abandoned soon after being found.

Trends in breeding male and calf presences

To infer potential post-whaling changes in the sperm whale population using Galápagos, we tested whether two proxies of reproductive activity— presence of breeding males and calves — increased from 1985 to 2014. Using analysis of covariance (ANCOVA), we modeled the proportion of female clusters with large males and with calves, separately, as a function of years (linear predictor), calendar months (categorical predictor) and their interaction ${ }^{4}$. The proportion of breeding males was calculated as the total number of males divided by the total number of adults (females and males) per month during Mode B surveys; similarly, the proportion of calves was calculated as the total number of calves divided by the total number females per month. We used months as units of analysis to avoid temporal correlation and ensure data independence.

Results

\footnotetext{
${ }^{4}$ Table S2
} 
From 7842 high-quality photographs, we identified 1953 individual females and 138 individual males off the Galápagos Islands between 1985 to $2014^{5}$. Sighting rates of sperm whales varied throughout this period. They were notably high in the 1980 's, declined through the 1990 's, dropped to zero in the 2000's, and slightly rose again in the early 2010's (Fig. 2 a). We found a larger proportion of males in late 1990's and 2010's, and only males in the 2000's ${ }^{6}$. Feeding success was variable across the years (Fig. 2 b). Particularly low defecation rates happened around El Niño years (e.g. 1987, 1997, 2014; Fig. 1), and particularly high rates in years when only males were found (e.g. $2002^{7}$ ). The proportion of time females spent foraging in comparison to socializing decreased by about a third from the 1980's to the 1990's and, although data are few, it seemed to remain low after that (Fig. 2 c).

Size of clusters of adults varied across years, with a decrease from the 1980's to 1990's followed by a slight increase towards the 2010's (Fig. 2 d). The average group size of females and immatures peaked about 1990, and again in the 2010's (Fig. 2 e). The sex ratio (number of identified males/females) was low in the 1980's (Fig. 2 f), mirroring the large number of females found at the beginning of the study $^{8}$. The sex ratio increased during the 1990's and early 2000's, as females left the area and more males arrived ${ }^{9}$. The males present in this period were mostly foraging since groups of females were nearly absent at the time (Fig. 2 i). More recently, in the 2010's, the sex ratio decreased as large groups of females returned to the Islands (Fig. 2 e).

The presence of large, mature males in close proximity to females was high in early 1980's and declined to zero in the early 2000's (as the females abandoned the area), and rose again in 2013 and 2014 (Fig. $2 \mathrm{~h}, \mathrm{i}$ ). The trend in the proportion of calves in the clusters visually mirrored the proportion of breeding males' pattern (Fig. 2 g). However, none of the 6 tested ANCOVA models suggested statistically significant increase in proportions of clusters with breeding males or calves per year or per month at the $5 \%$ level $^{10}$.

The fine-scale distribution of whales around the archipelago also changed across decades ${ }^{11}$ (Fig. 3). Groups of females and immatures were more often sighted off the northwestern portion of the archipelago in the 1980's (Fig. 3 a), off the northern and northeastern portions in the 1990's (Fig. 3 b),

\footnotetext{
${ }^{5}$ Table S1

${ }^{6}$ Fig. S2

${ }^{7}$ Fig. S2

${ }^{8}$ Fig. S2

${ }^{9}$ Fig. S2

${ }_{10}$ Table S2

${ }^{11}$ Fig. S3
} 
but switched to the southern and southwestern portions from the 2000's on (Fig. 3 c). Solitary mature males, or small groups of 2 to 3 bachelor males (survey Mode C), were sighted only in the 1990's and 2010's. In such years, while some male encounters occurred overlapping the distribution of female groups, foraging males were also found by themselves in other parts of the archipelago. This was particularly the case in 1997 when females were completely absent and males were found off north and northeast.

Discussion

The emerging picture from our three-decade offshore research is the waxing and waning of the sperm whale population in the waters off Galápagos Islands. Sperm whale occurrence was common in the 1980's, declined over the 1990's to a complete abandonment in the 2000's, and showed a modest increase in the 2010's. Furthermore, the two sexes showed somewhat different patterns. In what follows, we consider how the fluctuation of population descriptors combined may reflect the nomadic behaviour of sperm whales in response to environmental dynamics and whaling operations in the eastern tropical Pacific.

Decadal patterns

Sperm whales were relatively common off the Galápagos in the 1980's, following the end of commercial whaling in the eastern tropical Pacific in 1981 (Ramirez 1989). During this time, both males and females used Galápagos waters to forage and socialize, often forming large groups with a relatively high proportion of calves. They were mostly seen in the western and northwestern portion of the archipelago, where cold, upwelling waters are usually found (Palacios 2002; Schaeffer et al. 2008). This suggests that food availability may have attracted and sustained whales in the waters off Galápagos. In the 1990 's, their numbers started to decrease, especially the groups of females with immatures and calves. Solitary, foraging males became more common, mostly in the northern portion of the archipelago, even without females (suggesting some degree of reproductive philopatry; see Mesnick et al. 2011). With fewer groups of females, single males experienced higher feeding success. This might be due to a reduction in resource competition or to a shift in the behavioural state of males from socializing to foraging, both consequences of the absence of groups of females in the area. 
But by the late 1990's and early 2000's, sperm whales were practically gone. Sightings became rare: females were no longer seen, and males tended to disperse (see Alexander et al. 2016), except for occasional solitary large males or small groups of bachelors. In consequence, group and cluster sizes decreased along with calf sightings and socializing females. The nearly complete absence of females in our surveys, supported by a nearly complete absence of opportunistic whale sightings in the area ${ }^{12}$, motivated us to survey other areas, such as Chile and the Sea of Cortez (see Whitehead 2008; Cantor et al. 2016b). After this gap in our sampling effort off Galápagos in the late 2000's, whales started to return. In the 2010's, they were more concentrated in the southern and southwestern part of the archipelago, in larger groups of females with an apparent increased proportion of calves and mature males. Given few differences in prey size and diet composition (Ruiz-Cooley et al. 2004), largely discrete foraging distributions of males and females suggest strategies for reducing intraspecific competition (Christal et al. 1998). While at very larger scales sperm whales' movements are characterized by male-biased dispersal and female geographic and social group philopatry (see Alexander et al. 2016), prey availability is a major driver of their displacement over relatively smaller scales (Whitehead et al. 2008; Mizroch and Rice 2012). This aligns with the changes in overall patterns of occurrence that we observed off the Galápagos along the last three decades.

Fluctuation of prey availability

Sperm whale diet is mostly composed of deep-sea squids, such as histioteuthids and the Humboldt squid (Dosidicus gigas, d'Orbigny (in 1834-1847), 1835) (Clarke 1977). Given the sperm whales' large food requirements (400-1,000 kg/day; Clarke et al. 1993) and the patchiness, short lifecycles and unpredictability of their prey, they move constantly at small and large scales (Whitehead and Rendell 2004; Whitehead et al. 2008), from areas of low to high feeding success (Whitehead 1996). The substantial fluctuations in fine-scale distribution, sighting rates, and feeding rates off Galápagos suggest major temporal and spatial variation in prey availability.

Sperm whales are often associated with thermal discontinuities and steep slopes (Jaquet 1996). These are usually up- or downwelling areas (Gulland 1974) where productivity, and hence cephalopod abundance, is enhanced (see Jaquet 1996). The Galápagos and western South American shelf break

\footnotetext{
${ }^{12}$ G. Merlen, personal observation
} 
present such bathymetric ${ }^{13}$ and oceanographic features, and the Humboldt and other squid species, are distributed throughout these waters (see Taipe et al. 2001; Ibáñez et al. 2009; Baque-Menoscal et al. 2012). However, the distribution and abundance of Humboldt squid throughout the Eastern Pacific fluctuate greatly in response to oceanic changes induced by ENSO. Warm ENSO events have strong negative impact (Taipe et al. 2001; Markaida 2006a; Waluda and Rodhouse 2006), whereas cool ENSO events intensify upwelling and phytoplankton productivity which impact Humboldt squid distribution and abundance positively, although not immediately (Markaida 2006b).

In years of mild warm ENSO events (e.g. 1987, 2014), the annual feeding rate of female sperm whales dropped significantly (see also Whitehead 1989; Smith and Whitehead 1993) and their fine-scale distribution shifted away from the core productive region west of the Galápagos archipelago. During strong warm ENSO events, consequences were more drastic. For instance, in the 1997-1898 event the Humboldt squid fisheries off Peru and the Gulf of California collapsed (Markaida 2006b; Taipe et al. 2001), and a similar sharp decrease in deep-sea squids may have happened around the Islands as suggested by the dramatic decreases in phytoplankton production and in the presence of seabirds and marine mammals (Wolff et al. 2012). During the cool ENSO event of 1988-1989, the sperm whale feeding rates were higher than in previous years, and they were sighted more often at the productive core of the Islands. This suggests high availability of prey associated to intensified upwelling during that period. However, during the 1999-2001 mild cool ENSO, sperm whales were absent from the archipelago and were rare in the area after over a decade. This is remarkable as they were present and abundant in 1985, only two years after the strongest warm ENSO event of the century (Trillmich and Limberger 1985).

The whales' immediate responses to decreased food availability include changes in aggregation behavior, diet composition, and short-scale movements (e.g. Flinn et al. 2002). But when food availability drops below a critical threshold, the benefits of undertaking large-scale movements towards a new habitat may outweigh the cost of staying in a lower quality habitat (Whitehead 2000). In 1982, for instance, sperm whales off Peru moved south to the more productive waters off Chile (Ramirez and Urquizo 1985). Such large-scale movements in response to low food availability may explain the complete absence of female and juvenile sperm whales in years following the 1997-1998 warm ENSO event as the Galápagos waters likely became not productive enough, unsuitable for such larger groups.

\footnotetext{
${ }^{13}$ Fig. S1
} 
Therefore, we suggest that emigration and immigration, as opposed to changes in mortality and survival rates, are the most likely drivers of the fluctuation in sperm whale occurrence around the Galápagos Islands (see also Whitehead et al. 1997; Cantor et al. 2016b). There is no evidence for abnormally high mortality rates in the 1990's, after the cessation of the whaling industry (see Whitehead et al. 1997). Additionally, their long life cycles (e.g. Whitehead 2003) make 30 years too short of a period for a rapid population increase by abnormally high birth rates to be the cause of increased whale presence in the 2010's. Although it remains uncertain where the whales come from and go to, there have been a number of re-sightings of individuals moving $1000-2000 \mathrm{~km}$ from Galápagos to the coastal waters of Ecuador and Peru, as well as a few moving $4000 \mathrm{~km}$ to and from the Gulf of California and northern Chile (Dufault and Whitehead 1995; Whitehead et al. 2008; Cantor et al. 2016b). While such large-scale displacements seem normal sperm whale responses to fluctuation in prey availability, they were likely exacerbated in the post-whaling period by artificially large disjunctions between resource availability and whale densities.

\section{Ripple effects of whaling}

Whaling operations have been targeting sperm whale population in the eastern tropical Pacific since the late 1790 's. In the $19^{\text {th }}$ century, whaling activities around the Galápagos Islands, particularly by U.S. whalers, targeted both male and female sperm whales (Hope and Whitehead 1991). Whaling from open boats with hand-held harpoons declined in the latter $19^{\text {th }}$ Century, and sperm whales world-wide received something of a reprieve until modern commercial whaling with harpoon guns fired from dieselpowered catcher vessels began targeting sperms intensively in the 1950's (e.g. Whitehead 2002). In modern whaling, the preferred targets were large, mature males. This was particularly the case for the shore stations catching sperm whales off Peru and Chile (Ramirez 1989), as well as likely also true for pirate whalers working further from shore. The coastal areas off western South America where once whales abounded were heavily depleted, especially of mature males (Ramirez 1989). In consequence, these productive areas became available for the fewer remaining whales.

Sperm whale distribution is, at least partially, determined by density-dependent habitat selection (Whitehead 2000). Therefore, opening such a niche in coastal waters may have further motivated the abandonment of the Galápagos waters just a little west of the prime whaling grounds (Whitehead et al. 1997). This potential eastward emigration to the more productive coastal waters agrees with the observed 
absence of female and juveniles off Galápagos in the late 1990's and 2000's. After the whaling moratorium, the population was expected to increase even if very slowly. If this were the case, coastal waters would saturate over time, stimulating the repopulation of peripheral areas, perhaps being reflected in the return of sperm whales to Galápagos waters in the early 2010's. Our recent data suggest a very slight, although not significant, increase in the presence of large males and calves off Galápagos. An increased proportion of calves would be a consequence of the increased number of breeding males if their low numbers in the 1980's, following intense male-based whaling in the region (Ramirez 1989), reduced pregnancy rates (Whitehead et al. 1997).

Although it is possible that sperm whale populations are slowly recovering, even rigorous evaluation of recent and historical data on population dynamics leaves the question open for debate (e.g. Whitehead 2002; Baker and Clapham 2004). We emphasize that our three-decade study is a relatively short period in the sperm whale life span. Sperm whales are long-lived ( $>70$ years old; Whitehead 2003) and slow-reproducing animals. They have late sexual maturity (females at about 9 years, males at about 20 years) and long reproductive cycle (14 to 16-month gestation period, e.g. Best et al. 1984), and very low calving rates ( 0.2 calf per mature female/year; Best et al. 1984). Therefore, detecting population recovery following the end of industrial whaling, if any, requires substantial amount of empirical data spanning multiple generations, which is particularly challenging to collect given the spatiotemporal scales used by sperm whales.

\section{Conclusions}

Our findings suggest the interaction between environmental processes affecting prey availability and anthropogenic pressure have driven substantial changes in occurrence of sperm whales off the Galápagos Islands. The local population fluctuation over the last 30 years reflects the large-scale movement of sperm whales from and to the Galápagos, as well as within the Galápagos region, likely in response to changes in prey availability. Additionally, these movements may include lagged responses to the end of the whaling industry at the onset of our research in early 1980's. Our findings emphasize the magnitude of the spatiotemporal scales that are relevant for such a mobile, pelagic species. Affording a clearer picture of the population dynamics post-whaling era requires continuing research effort over wide areas and long periods of time. 
Acknowledgements

Many thanks to M. Kean and F. Félix for field work logistics; to the many volunteer crewmembers over the last 30 years for their hard work; to J. Christal, N. Jaquet, S. Lusseau, A. Coakes, T. Arnbom, S. Waters, and L. Hoogenboom for assistance with photo-identification; and the Ministerio de Defensa Nacional (DIGEIM), Ministerio del Ambiente, and Dirección del Parque Nacional Galápagos (DPNG) for several permits to operate in Ecuadorian waters and carry out research on sperm whales. MC received doctoral scholarships by Conselho Nacional de Desenvolvimento Científico e Tecnológico (\#202581/2011-0) and Killam Trusts, and the Amy R. Samuels Cetacean Behaviour and Conservation Award by the Animal Behaviour Society. AE was supported by the Dalhousie University Faculty of Graduate Studies and the Nova Scotia Graduate Scholarship. HW acknowledges funding by Natural Sciences and Engineering Research Council of Canada, the National Geographic Society, the International Whaling Commission, the Whale and Dolphin Conservation Society, Cetacean Society International and the Green Island Foundation.

References

Adler, G. 1998. Impacts of resource abundance on populations of a tropical forest rodent. Ecology, 79(1): 242-254. doi: 10.1890/0012-9658(1998)079[0242:IORAOP]2.0.CO;2.

Alexander, A., Steel, D., Hoekzema, K., Mesnick, S.L., Engelhaupt, D., Kerr, I., Payne, R., and Baker, C.S. 2016. What influences the worldwide genetic structure of sperm whales (Physeter macrocephalus)?. Mol. Ecol. 25(12): 2754-2772. doi: 10.1111/mec.13638.

Baque-Menoscal, J., Páez-Rosas, D., and Wolff, M. 2012. Hábitos alimentarios de dos peces pelágicos Thunnus albacares y Acanthocybium solandri de la Reserva Marina de Galápagos. Rev. Biol. Mar. Ocean 47(1):1-11. doi: http://dx.doi.org/10.4067/S0718-19572012000100001.

Barber, R.T., and Chavez, F.P. 1983. Biological consequences of El Niño. Science, 222(4629): 12031210. doi: $10.1126 /$ science.222.4629.1203.

Baker, C.S., and Clapham, P.J. 2004. Modelling the past and future of whales and whaling. Trends Ecol. Evol. 19(7): 365-371. doi: 10.1016/j.tree.2004.05.005.

Best, P.B., Canham, P.A.S., and Macleod, N. 1984. Patterns of reproduction in sperm whales, Physeter macrocephalus. Rep. Intl. Whaling Comm. 6:51-79. 
Best, P.B. 1979. Social organization in sperm whales, Physeter macrocephalus. In Behavior of Marine Animals: current Perspectives in Research. Edited by H.E. and B.L. Olla. Springer, Boston. pp. 227289.

Blake, J., and Loiselle, B. 1991. Variation in resource abundance affects capture rates of birds in three lowland habitats in Costa Rica. The Auk, 108(1):114-130. doi: http://www.jstor.org/stable/4088055.

Bodmer, R. 1990. Responses of ungulates to seasonal inundations in the Amazon floodplain. J. Trop.

Ecol. 6(2): 191-201. doi: 10.1017/S0266467400004314.

Boyce, M., Haridas, C., Lee, C., the NCEAS Stochastic Demography Working Group. 2006.

Demography in an increasingly variable world. Trends Ecol. Evol. 21(3):141-148. doi:

10.1016/j.tree.2005.11.018.

Ca,i W., Borlace, S., Lengaigne, M., Van Rensch, P., Collins, M., Vecchi, G., Timmermann, A., Santoso, A., McPhaden, M.J., Wu, L., and England, M.H. 2014. Increasing frequency of extreme E1 Niño events due to greenhouse warming. Nat. Clim. Change, 4:111-116. doi: 10.1038/nclimate2100.

Cantor, M., Whitehead, H., Gero, S., and Rendell, L. 2016a. Data from: Cultural turnover among Galápagos sperm whales [online]. Dryad repository: http://dx.doi.org/10.5061/dryad.8jj26

Cantor, M., Whitehead, H., Gero, S., and Rendell, L. 2016b. Cultural turnover among Galápagos sperm whales. R. Soc. Open. Sci. 3: 160615. doi: http://dx.doi.org/10.1098/rsos.160615

Christa,1 J., and Whitehead, H. 1997. Aggregations of mature male sperm whales on the Galapagos Islands breeding ground. Mar. Mamm. Sci. 13(1): 59-69. doi: 10.1111/j.1748-7692.1997.tb00612.x

Christal, J., Whitehead, H., and Lettevall, E. 1998. Sperm whale social units: variation and change. Can. J. Zool. 76(8):1431-1440. doi: 10.1139/z98-087.

Clapham, P.J., and Baker, C.S. 2002. Modern whaling. In Encyclopedia of Marine Mammals. Edited by

W.F. Perrin, B. Würsig, and J.G.M. Thewissen. Academic Press, New York. pp. 1328-1332.

Clarke, M. 1977. Beaks, nets and numbers. Symp. Zool. Soc. Lond. 38:89-126.

Clarke, M., Martins, H., and Pascoe, P. 1993. The diet of sperm whales (Physeter microcephalus Linnaeus 1758) off the Azores. Philos. Trans. R. Soc. Lond. B Biol. Sci. No. 339(1287):67-82. doi: 10.1098/rstb. 1993.0005 .

Daszak, P., Cunninghame, A., and Hyat, A. 2003. Infectious disease and amphibian population declines. Divers. Distrib. 9(2):141-150. doi: 10.1046/j.1472-4642.2003.00016.x. 
de Little, S., Bradshaw, C., McMahon, C., and Hindell, M. 2007. Complex interplay between intrinsic and extrinsic drivers of long-term survival trends in southern elephant seals. BMC Ecol. 7(1): 3 doi: $10.1186 / 1472-6785-7-3$.

Dufault, S., and Whitehead, H. 1995. The geographic stock structure of female and immature sperm whales in the South Pacific. Rep. Intl. Whaling Comm. 45: 401-405.

Flinn, R., Trites, A., and Gregr, E. 2002. Diets of fin, sei, and sperm whales in British Columbia: an analysis of commercial whaling records, 1963-1967. Mar. Mamm. Sci. 18(3):663-379. doi: 10.1111/j.1748-7692.2002.tb01065.x.

Fretwell, S., and Lucas, H. 1969. On territorial behavior and other factors influencing habitat distribution in birds. Acta Biotheor. 19(1):16-36. doi: 10.1007/BF01601953.

Frick, W., Pollock, J., Hicks, A., Langwig, K., Reynolds, D., Turner, G., Butchkoski, C., and Kunz, T. 2010. An emerging disease causes regional population collapse of a common North American bat species. Science, 329(5992):679-682. doi: 10.1126/science.1188594.

Gaillard, J., and Yoccoz, N. 2016. Temporal variation in survival of mammals: a case of environmental canalization? Ecology, 84(12):3294-3306. doi: 10.1890/02-0409.

Gulland, J.A. 1974. Distribution and abundance of whales in relation to basic productivity. In The whale problem. Edited by W.E. Schevill. Harvard University Press, Cambridge. pp. 27-52.

Hope, P.L., and Whitehead H. 1991. Sperm whales off the Galápagos Islands during the period 18301850 and comparisons with modern studies. Rep. Intl. Whaling Comm. 41:273-283.

Hosmer, D., and Lemeshow, S. 2000. Applied logistic regression. John Wiley \& Sons, New York.

Ibáñez, C.M., Camus, P.A., and Rocha, F.J. 2009. Diversity and distribution of cephalopod species off the coast of Chile. Mar. Biol. Res. 5(4): 374-384. doi: 10.1080/17451000802534873.

Jaquet, N. 1996. How spatial and temporal scales influence understanding of sperm whale distribution: a review. Mammal Rev. 26:51-65. doi: 10.1111/j.1365-2907.1996.tb00146.x.

Lack, D. 1966. Population studies of birds. Clarendon Press, Oxford.

Laurie, W., and Brown, D. 1990. Population biology of marine iguanas (Amblyrhynchus cristatus). III. Factors affecting survival. J. Anim. Ecol. 59(2):545-568. doi: 10.2307/4880.

Lavery, T.J., Roudnew, B., Gill, P., Seymour, J., Seuront, L., Johnson, G., Mitchell, J.G., and Smetacek, V. 2010. Iron defecation by sperm whales stimulates carbon export in the Southern Ocean. Proc. R. Soc. Lond. B Biol. Sci. 277(1699). doi: 10.1098/rspb.2010.0863. 
Łomnicki, A. 1988. Population ecology of individuals. Princeton University Press, New Jersey.

Markaida, U. 2006a. Food and feeding of jumbo squid Dosidicus gigas in the Gulf of California and adjacent waters after the 1997-98 El Niño event. Fish. Res. 79(1-2):16-27. doi:

10.1016/j.fishres.2006.02.016.

Markaida, U. 2006b. Population structure and reproductive biology of jumbo squid Dosidicus gigas from the Gulf of California after the 1997-1998 El Niño Event. Fish. Res. 79(1-2):28-37. doi:

10.1016/j.fishres.2006.02.009.

Mathiopoulus ,J. 2003. Model-supervised kernel smoothing for the estimation of spatial usage. Oikos, 102(2):367-377. doi: 10.1034/j.1600-0706.2003.12528.x.

Mesnick, S.L., Taylor, B.L., Archer, F.I., Martien, K.K., Trevino, S.E., Hancock-Hanser, B.L., Medina S.C.M., Pease, V.L., Robertson, K.M., Straley, J.M., Baird, R.W., Calambokidis, J., Schorr, G.S., Wade, P., Burkanov, V., Lunsford, C.R., Rendell, L., and Morin P.A.W. 2011. Sperm whale population structure in the eastern and central North Pacific inferred by the use of single-nucleotide polymorphisms, microsatellites and mitochondrial DNA. Mol. Ecol. Res. 11: 278-298. doi:c10.1111/j.1755-0998.2010.02973.x.

Mizroch, S., and Rice, D. 2013. Ocean nomads: distribution and movements of sperm whales in the North Pacific shown by whaling data and discovery marks. Mar. Mamm. Sci. 29(2):136-165. doi:

10.1111/j.1748-7692.2012.00601.x.

Moore, S. 2005. Long-term environmental change and marine mammals. In Marine mammal research: conservation beyond crisis. Edited by J. Reynolds, W. Perrin, R. Reeves, S. Montgomery, and T. Ragen. Johns Hopkins University Press, Baltimore. pp. 137-147.

Nigmatullin, C., Nesis, K., and Arkhipkin, A. 2001. A review of the biology of the jumbo squid Dosidicus gigas (Cephalopoda: Ommastrephidae). Fish. Res. 54(1):9-19. doi: 10.1016/S01657836(01)00371-X.

NOAA. 2016. National Oceanic and Atmospheric Administration, Climate Prediction Center. Historical El Niño/La Niña episodes (1950-present) [online]. Available from http://www.cpc.noaa.gov/products/analysis_monitoring/ensostuff/ensoyears.shtml [accessed 24 August 2016]. 
Paine, R.T. 2006. Whales, interaction webs, and zero-sum ecology. In Whales, whaling, and ocean ecosystems. Edited by J.A. Estes, D.P Demaster, D.F. Doak, T.M. Williams, and R.L. Jr. Brownell. University of California Press, Berkeley. pp. 7-13.

Ramirez, P. 1989. Captura de cachalote en Paita, 1976-1981. Bol. Lima 63:81-88.

Ramirez, P., and Urquizo, W. 1985. Los cetáceos mayores y el fenómeno El Niño 1982-1983. In El Niño, su Impacto en la Fauna Marina, Boletín extraordinario. Edited by W.E. Arntz, A. Landa, and J. Tarazona. Noveno Congreso Latinoamericano de Zoología, Arequipa, Perú, 9-15 October 1983. Instituto del Mar, Callao. pp. 201-206.

Roman, J., Estes, J.A., Morissette, L., Smith, C., Costa, D., McCarthy, J., Nation, J.B., Nicol, S., Pershing, A., and Smetacek, V. 2014. Whales as marine ecosystem engineers. Front. Ecol. Environ. 12(7):377-385. doi: 10.1890/130220.

Rotella, J., Link, W., Chambert, T., Stauffer, G., and Garrott, R. 2012. Evaluating the demographic buffering hypothesis with vital rates estimated for Weddell seals from 30 years of mark-recapture data. J. Anim. Ecol. 81(1): 62-173. doi: 10.1111/j.1365-2656.2011.01902.x.

Ruiz-Cooley, R., Gendron, D., Aguíñiga, S., Mesnick, S., and Carriquiry, J. 2004. Trophic relationships between sperm whales and jumbo squid using stable isotopes of C and N. Mar. Ecol. Prog. Ser. 277:275-283. doi: 10.3354/meps277275.

Shuster, G. 1983. The Galapagos Islands: a preliminary study of the effects of sperm whaling on a specific whaling ground. Rep. Intl. Whaling Comm. 5:81-82.

Sinclair, A. 1996. Mammal populations: fluctuation, regulation, life history theory and their implications for conservation. In Frontiers of population ecology. Edited by R. Floyd, A. Sheppard, and P. De Barro. CSIRO, Collingwood. pp. 127-154.

Smith, S.C., and Whitehead, H. 1993. Variations in the feeding success and behaviour of Galápagos sperm whales (Physeter macrocephalus) as they relate to oceanographic conditions. Can. J. Zool. 71(10):1991-1996. doi: 10.1139/z93-283.

Smith, T.D., Reeves, R.R., Josephson, E.A., and Lund J.N. 2012. Spatial and seasonal distribution of American whaling and whales in the age of sail. PLoS ONE, 7(4): e34905. doi:10.1371/journal.pone.0034905.

Strutton, PG., and Chavez, F.P. 2000. Primary productivity in the equatorial Pacific during the 19971998 El Niño. J. Geophys. Res. 10(C11):26089-26101. doi: 10.1029/1999JC000056. 
Sutherland, W. 1996. From individual behaviour to population ecology. Oxford University Press, Oxford. Székely, T., and Bamberger, Z. 1992. Predation of waders (Charadrii) on prey populations: an exclosure experiment. J. Anim. Ecol. 61(2):447-456. doi: 10.2307/5335.

Taipe, A., Yamashiro, C., Mariategui, L., Rojas, P., and Roque, C. 2001. Distribution and concentrations of jumbo flying squid (Dosidicus gigas) off the Peruvian coast between 1991 and 1999. Fish. Res. 54(1):21-32. doi: 10.1016/S0165-7836(01)00377-0.

Trillmich, F., and Limberger, D. 1985. Drastic effects of El Niño on Galapagos pinnipeds. Oecol. 67(1):258-263. doi: 10.1007/BF00378445.

Villegas-Amtmann, S., McDonald, B., Páez-Rosas, D., Aurioles-Gamboa, D., and Costa, D. In press. Adapted to change: low energy requirements in a low and unpredictable productivity environment, the case of the Galápagos sea lion. Deep. Sea Res. II Trop. Stud. Ocean. doi: 10.1016/d.dsr2.2016.05.015.

Waluda, C., and Rodhouse, P. 2006. Remotely sensed mesoscale oceanography of the Central Eastern

Pacific and recruitment variability in Dosidicus gigas. Mar. Ecol. Prog. Ser. 310 310:25-32. doi:

$10.3354 / \operatorname{meps} 310025$.

Whitehead, H. 1990. Computer-assisted individual identification of sperm whale flukes. Rep. Intl. Whaling Comm. 12:71-77.

Whitehead, H. 1993. The behaviour of mature male sperm whales on the Galápagos breeding grounds.

Can. J. Zool. 71: 689-699.

Whitehead, H. 1996. Variation in the feeding success of sperm whales: temporal scale, spatial scale and relationship to migrations. J. Anim. Ecol. 65(4):429-438. doi: 10.2307/5778.

Whitehead, H. 1999. Variation in the visually observable behavior of groups of Galápagos sperm whales. Mar. Mamm. Sci. 15(4):1181-1197. doi: 10.1111/j.1748-7692.1999.tb00884.x.

Whitehead, H. 2000. Density-dependent habitat selection and the modeling of sperm whale (Physeter macrocephalus) exploitation. Can. J. Fish. Aquat. Sci. 57(1):223-230. doi: 10.1139/cjfas-57-1-223.

Whitehead, H. 2002. Estimates of the current global population size and historical trajectory for sperm whales. Mar. Ecol. Prog. Ser. 242:295-304. doi: 10.3354/meps242295.

Whitehead, H. 2003. Sperm whales: Social evolution in the ocean. Chicago University Press, Chicago. Whitehead, H., and Rendell, L. 2004. Movements, habitat use and feeding success of cultural clans of South Pacific sperm whales. J. Anim. Ecol. 73(1):190-196. doi: 10.1111/j.1365-2656.2004.00798.x. 
Whitehead, H., and Weilgart, L.S. 1991. Patterns of visually observable behaviour and vocalizations in groups of female sperm whales. Behaviour, 118(3/4):275-296. Available from http://www.jstor.org/stable/4534968 [accessed 17 June 2016].

Whitehead, H., Papastavrou, V., and Smith, S. 1989. Feeding success of sperm whales and sea-surface temperatures off the Galápagos Islands. Mar. Ecol. Prog. Ser. 53(2):201-203. doi:

$10.3354 /$ meps053201.

Whitehead, H., Christal, J., and Dufault, S. 1997. Past and distant whaling and the rapid decline of sperm whales off the Galápagos Islands. Conserv. Biol. 11(1):1387-1396. doi: 10.1046/j.1523-

1739.1997.96246.x.

Whitehead, H., Coakes, A., Jaquet ,N., and Lusseau, S. 2008. Movements of sperm whales in the tropical Pacific. Mar. Ecol. Prog. Ser. 361:291-300. doi: 10.3354/meps07412.

Wilson, E.O., and Bossert, W.H. 1971. A primer of population biology. Sinauer Associates, Sunderland. Wolff, M., Ruiz, D., and Taylor, M. 2012. El Niño induced changes to the Bolivar Channel ecosystem (Galápagos): comparing model simulations with historical biomass time series. Mar. Ecol. Prog. Ser. 448:7-22. doi: 10.3354/meps09542. 
Figure captions

Figure 1. Trimestral El Niño Southern Oscillation Index (ONI) between 1970 and 2015. Black and light grey straight lines indicate the +0.5 and -0.5 threshold for warm ENSO and cool ENSO events, respectively. Strong warm ENSO events (1982-1983, 1997-1998, and 2015-2016) are indicated by black points and strong cool ENSO events (1973-1974, 1975-1976, and 1988-1989) are indicated by grey points. Data from The Climate Prediction Center (NOAA, 2016).

Figure 2. Temporal distribution of nine descriptors of population dynamics of sperm whales (Physeter macrocephalus) off the Galápagos Islands, for the years between 1985-2014 data were available. Whiskers represent standard errors (SE). Subplot letters match their definitions in the Methods section. (a) Sighting rates as number of encounters by total hours of searching; (b) Feeding rate as proportion of defecation records; (c) Behavioral ratio as number of hours females spent foraging by hours socializing; (d) Cluster size as number of females and immatures in close proximity at the surface; (e) Group size as number of females and immatures seen together over days; (f) Sex ratio as number of photo-identified males per females; (g) Calf proportion as number of clusters of females with calves; (h) Breeding male proportion as number of clusters of females with mature males; (i) Female clusters as number of clusters containing (black) or not (white) mature males.

Figure 3. Decadal fine-scale distribution of groups of sperm whales (Physeter macrocephalus) off the Galápagos Islands. Color code indicates kernel densities for groups of females and immatures; black circles indicate first position of group sightings of small groups with only males (note that no such groups were found in the 1980's); grey shades represent the islands and black contours around them indicate 1 000m isobaths. The following years with enough spatial data were grouped by decades as (a) 1985, 1987, 1989; (b) 1991, 1995, 1997; and (c) 2013, 2014. 


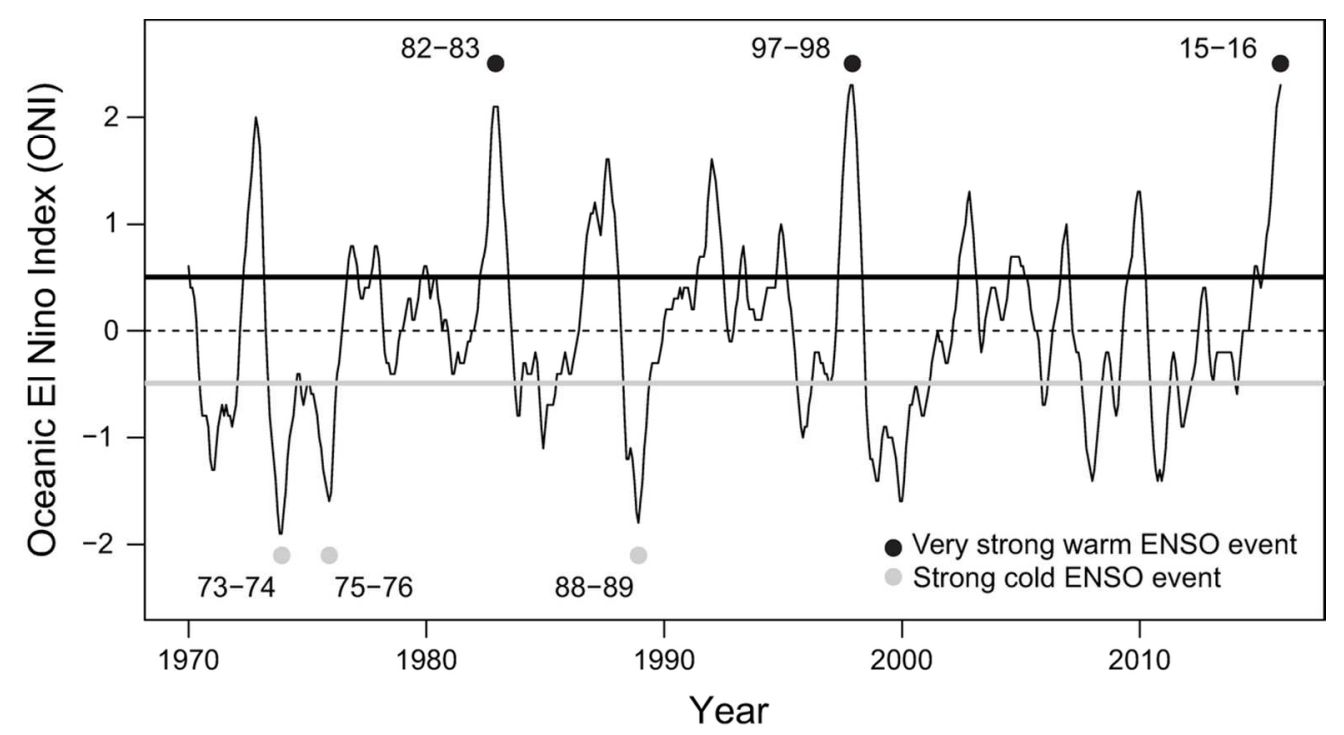

Figure 1. Trimestral EI Niño Southern Oscillation Index (ONI) between 1970 and 2015. Black and light grey straight lines indicate the +0.5 and -0.5 threshold for warm ENSO and cool ENSO events, respectively. Strong warm ENSO events (1982-1983, 1997-1998, and 2015-2016) are indicated by black points and strong cool ENSO events (1973-1974, 1975-1976, and 1988-1989) are indicated by grey points. Data from The Climate Prediction Center (NOAA, 2016).

$107 \times 59 m m(300 \times 300$ DPI $)$ 

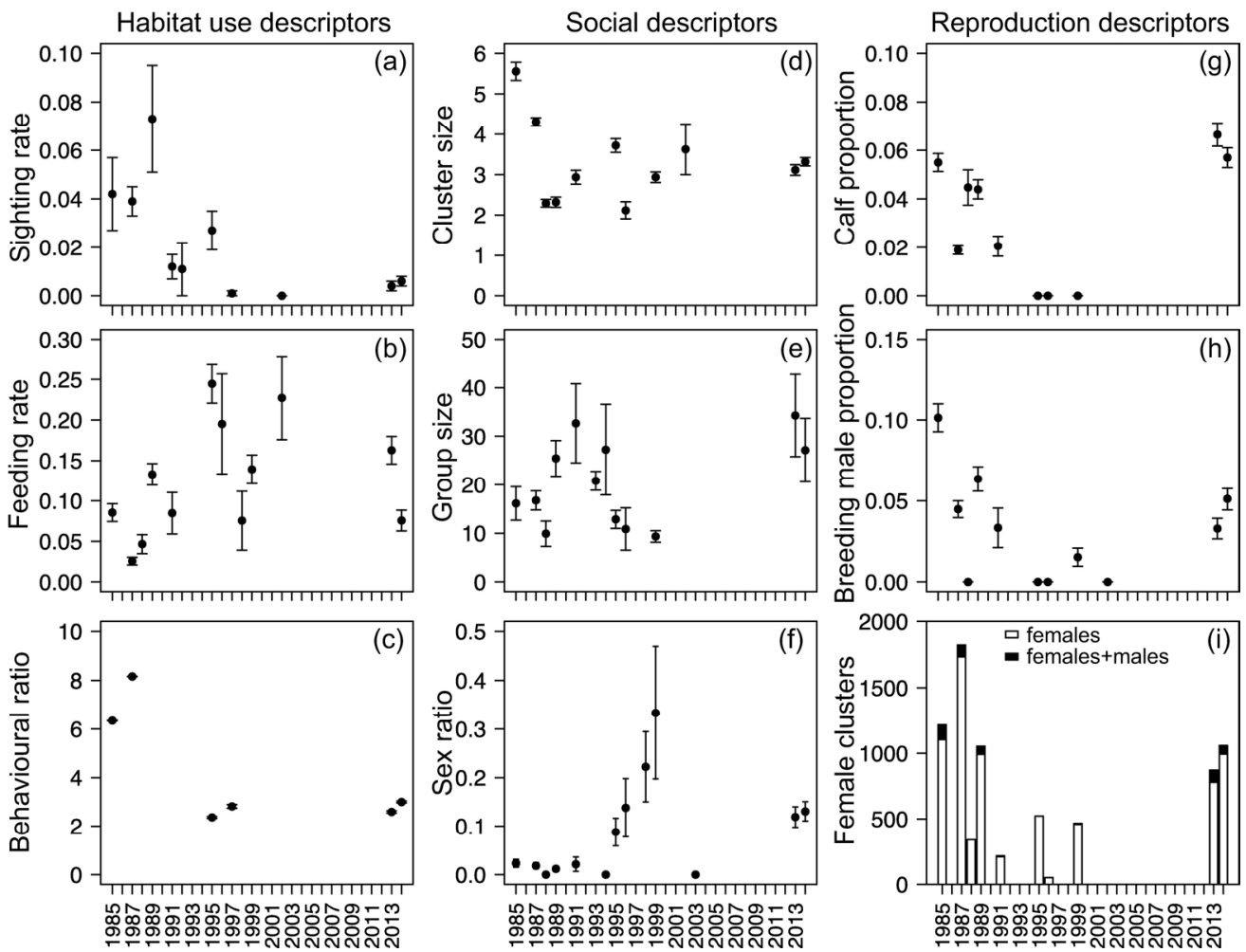

Figure 2. Temporal distribution of nine descriptors of population dynamics of sperm whales (Physeter macrocephalus) off the Galápagos Islands, for the years between 1985-2014 data were available. Whiskers represent standard errors (SE). Subplot letters match their definitions in the Methods section. (a) Sighting

rates as number of encounters by total hours of searching; (b) Feeding rate as proportion of defecation records; (c) Behavioral ratio as number of hours females spent foraging by hours socializing; (d) Cluster size as number of females and immatures in close proximity at the surface; (e) Group size as number of females and immatures seen together over days; $(f)$ Sex ratio as number of photo-identified males per females; $(g)$

Calf proportion as number of clusters of females with calves; $(h)$ Breeding male proportion as number of clusters of females with mature males; (i) Female clusters as number of clusters containing (black) or not (white) mature males.

$172 \times 131 \mathrm{~mm}(300 \times 300 \mathrm{DPI})$ 

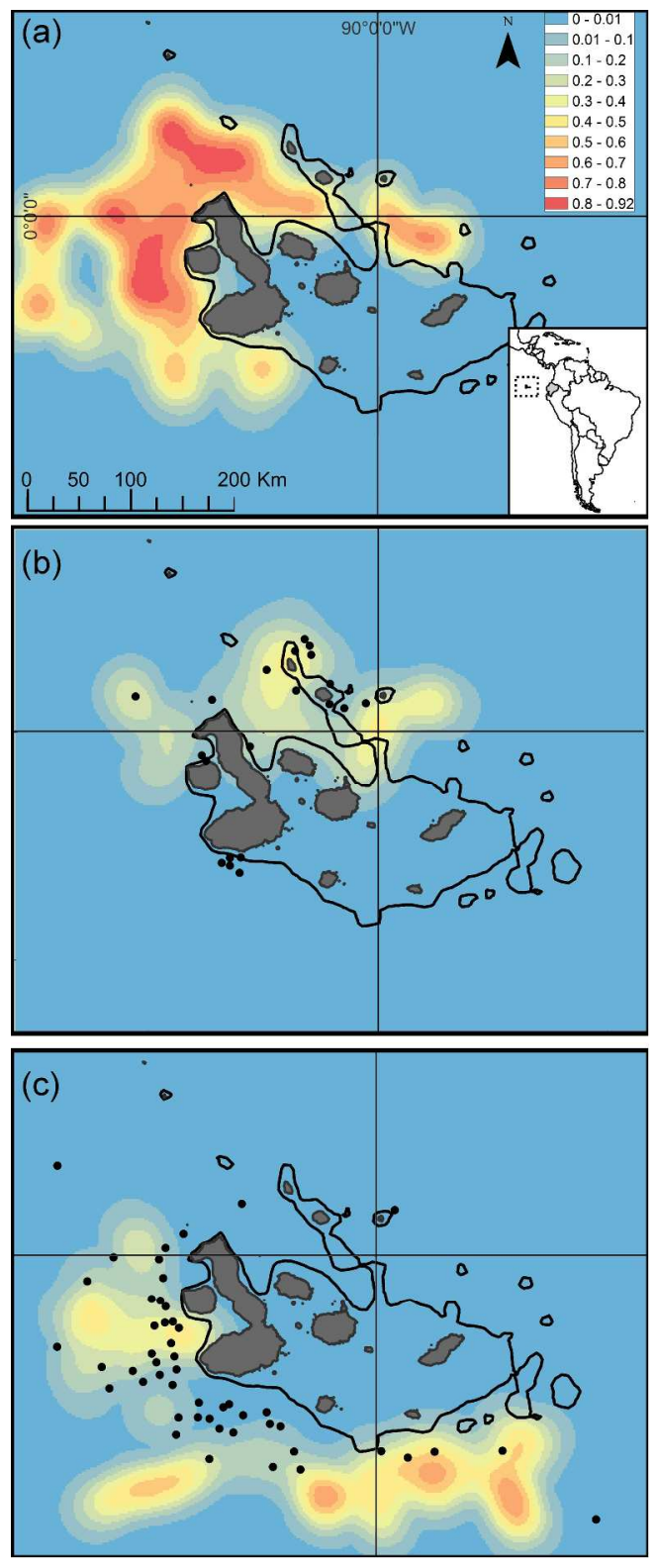

Figure 3. Decadal fine-scale distribution of groups of sperm whales (Physeter macrocephalus) off the Galápagos Islands. Color code indicates kernel densities for groups of females and immatures; black circles indicate first position of group sightings of small groups with only males (note that no such groups were found in the 1980's); grey shades represent the islands and black contours around them indicate $1000 \mathrm{~m}$ isobaths. The following years with enough spatial data were grouped by decades as (a) $1985,1987,1989$; (b) 1991, 1995, 1997; and (c) 2013, 2014.

$260 \times 633 \mathrm{~mm}$ ( $300 \times 300$ DPI) 